\title{
Correction to: Motivations, benefits and challenges on ISO/IEC 17025 accreditation of higher education institution laboratories
}

\author{
Inês Hexsel Grochau ${ }^{1} \cdot$ Carla Schwengber ten Caten ${ }^{1} \cdot$ Maria Madalena de Camargo Forte $^{1}$
}

Published online: 18 June 2018

(C) Springer-Verlag GmbH Germany, part of Springer Nature 2018

\section{Correction to: Accreditation and Quality Assurance}

https://doi.org/10.1007/s00769-018-1317-9

Unfortunately, figure 3 was incorrectly published in the original publication and the correct version is updated here (Fig. 3). The original article has been corrected.

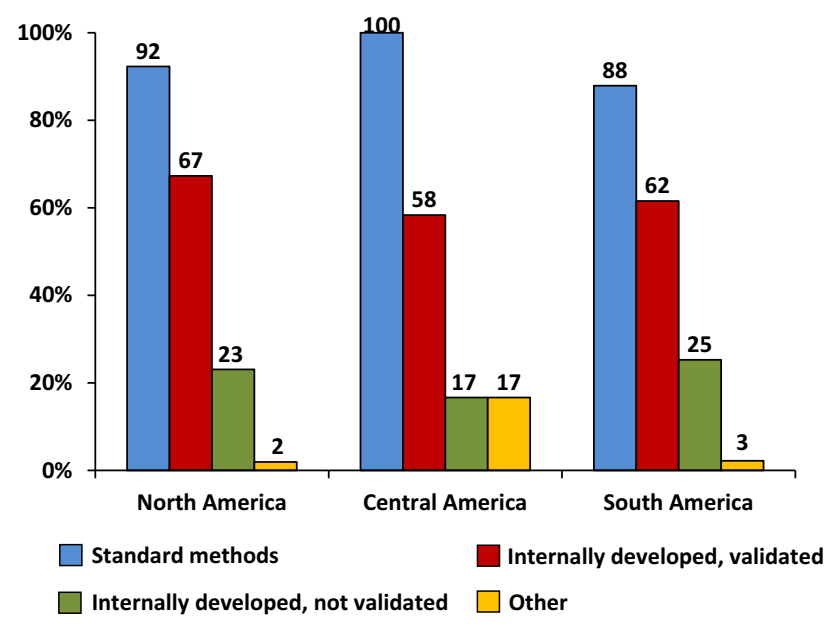

Fig. 3 Methods used by the laboratory per region

The original article can be found online at https:// doi.org/10.1007/s00769-018-1317-9.

Inês Hexsel Grochau inesgrochau@gmail.com

1 Universidade Federal do Rio Grande do Sul, Porto Alegre, RS, Brazil 